\title{
DIFERENTES CONCENTRAÇÕES DE ALUMÍNIO EM SOLUÇÃO NUTRITIVA NA TOLERÂNCIA DE CULTIVARES DE ARROZ ${ }^{(1)}$
}

\footnotetext{
CARLOS EDUARDO DE OLIVEIRA CAMARGO (2), OCTÁVIO BENTO DE ALMEIDA CAMARGO (2), Secão de Arroz e Cereais de Inverno, e DERLY MACHADO DE SOUZA. Divisão de Plantas Alimenticias Basicus, Instituto Agronômico.
}

\section{RESUMO}

Foram estudados onze cultivares de arroz em soluções nutritivas contendo seis níveis de alumínio (0, 10, 20, 30, 40 e 50mg/litro) mantendo-se constante a temperatura de $30 \pm 1^{\circ} \mathrm{C}$ e o $\mathrm{pH}$ das soluções igual a 4,0. A tolerância foì medida pelo comprimento méđio da raiz primária central, peso seco total das folhas e das raizes de vinte plantas após serem cultivadas durante dez dias em soluções nutritivas contendo diferentes concentrações de aluminio. A presença de qualquer das doses de alumínio foi prejudicial a todos os cultivares estudados. Os cultivares IR-8, IR-841 e IAC-899 foram sensiveis quando se empregaram 10mg/litro de Al3r nas soluções, ao passo que os cultivares IAC-435, IAC-120, IAC-165, IAC-164, Pérola, Blue Bonnet, IAC-47 e IAC-25 mostraram-se tolerantes, mantendo essa tolerância mesmo quando se empregaram $20 \mathrm{mg} / 1$ itro de Ali3+ nas soluções. Todos os cultivares foram sensiveis quando foi aplicada a quantidade de aluninio equivilente a uma concentraçāo de $50 \mathrm{mg}$ /litro. Os teores de alumínio em partes por milhão aumentaram e os teores de $\mathrm{Ca}, \mathbf{M g}$ e $\mathbf{K}$ diminuíram na matéria seca da parte aérea de todos os cultivares à medida que se aumentaram as concentrações de Al nas soluções nutritivas.

\section{INTRODUÇÃO}

Muitas das variedades desenvolvidas pelo Instituto Internacional de Pesquisas de Arroz (IRRI), localizado nas Filipinas, foram selecionadas

(1) Recebido para publicação a 10 de setembro de 1983.

(2) Com bolsa de suplementação do CNPq. 
em solos relativamente férteis, expressando, portanto, o seu potencial produtivo em, no máximo, 25 a $30 \%$ da área cultivada com arroz no mundo (5).

$\mathrm{Na}$ realidade, milhões de hectares cultivados nos trópicos são representados por solos ácidos, sendo, nessas condições, a toxicidade causada pela presença do aluminio uma das principais causas da baixa produtividade do arroz e outras culturas. A obtenção de cultivares portadores de tolerância ao alumínio é de alto interesse nos diferentes programas de melhoramento dessas regiões (5).

Os cultivares de arroz IR-20, IR-1514A-E666, IR-1514A-E597 e Pata foram considerados sensiveis à toxicidade de alumínio quando se empregou um solo cujo $\mathrm{pH}$ foi diminuido para 4,0 a 4,3 pela adição de flor de enxofre. No mesmo experimento (1), os cultivares IR-442-2-58, IR-712-23-2, IR-665-8-3 e IR-1561-228-3 foram moderadamente sensiveis e IR-24, IR-1008-14-1, M-1-48, Monolaya e C-22-51, tolerantes.

Um método rápido para a identificação de plantas tolerantes ao alumínio (5) e de fácil reprodução, baseado na paralisação irreversível do meristema das raizes primárias do arroz no estádio de plântula, utilizando-se solução nutritiva, permitiu classificar os cultivares de arroz Monolaya e Blue Bonnet como tolerantes e, Colombia-1, CICA-4, IR-5, IR-8 e IR-665-23-3-1, como sensíveis. Empregando o mesmo método, CAMARGO et alii (2) classificaram os cultivares de arroz IAC-435, IAC-120, IAC-47, IAC-1246, IAC-25, IAC-165, IAC-164, Pérola, Batatais, Pratão Precoce e Blue Bonnet como tolerantes; Pratão, Dourado Precoce e CICA-8, como moderadamente tolerantes, e CICA-4, IR-42, IR-43, IR-45, IR-8, IAC-899, IR-665-4-5-5 e IR-841, como sensiveis.

Como o método desenvolvido na Universidade Estadual de Oregon e utilizado por MARTINEZ (5) e CAMARGO et alii (2) exige duas mediçōes das raízes primárias do arroz, devido ser a tolerância ao Al baseada no crescimento das raízes em solução nutritiva completa após a influência prejudicial do alumínio nas soluçóes de tratamento, o presente trabalho tem por objetivo desenvolver um método mais simples visando ao estudo da tolerância de cultivares de arroz a diferentes concentraçōes de Al em soluçōes nutritivas, dispensando uma das medições.

\section{MATERIAL E MÊTODOS}

As sementes dos onze cultivares estudados: IAC. 25 , IAC-120, IAC-164, IAC-165, Pérola, Blue Bonnet, IAC-47, IAC-899, IR-8, IR-841 e IAC-435 foram cuidadosamente lavadas com uma solução de hipoclorito de sódio a $10 \%$ e colocadas para germinar em caixas de Petri por 48 horas. Após esse tempo, as radiculas estavam iniciando a emergência.

Foram escolhidas vinte sementes uniformes de cada cultivar e colocadas sobre o topo de seis telas de náilon. Cada uma das telas contendo 
as sementes dos onze cultivares foi colocada em contato com a solução nutritiva completa existente em seis vasilhas plásticas de 8,30 litros de capacidade cada uma.

A composição da solução nutritiva completa foi a seguinte: $\mathrm{Ca}\left(\mathrm{NO}_{3}\right)_{2}$ $4 \mathrm{mM} ; \mathrm{MgSO}_{4} 2 \mathrm{mM}$; $\mathrm{KNO}_{3} 4 \mathrm{mM}$; $\left(\mathrm{NH}_{4}\right)_{2} \mathrm{SO}_{4} 0,435 \mathrm{mM} ; \mathrm{KH}_{2} \mathrm{PO}_{*} 0,5 \mathrm{mM}$; $\mathrm{MnSO}_{4} 2,0 \mu \mathrm{M} ; \mathrm{CuSO}_{4} 0,3 \mu \mathrm{M} ; \mathrm{ZnSO}_{4} 0,8 \mu \mathrm{M} ; \mathrm{NaCl} 30_{\mu} \mathrm{M} ; \mathrm{Fe}-\mathrm{CYDTA}$ $10_{\mu} \mathrm{M}$; $\mathrm{Na}_{2} \mathrm{MoO}_{1} 0,1_{\mu} \mathrm{M}$ e $\mathrm{H}_{3} \mathrm{BO}_{3} \quad 10_{\mu} \mathrm{M}$. O nivel da solução nas vasilhas plásticas tocava na parte inferior da tela de náilon de maneira que as sementes foram mantidas úmidas e as radículas emergentes tinham um pronto suprimento de nutrientes. $\mathrm{O} \mathrm{pH}$ da solução foi previamente ajustado para 4,0 com solução de $\mathrm{H}_{2} \mathrm{SO}_{4} 1 \mathrm{~N}$. As soluçōes foram continuamente arejadas e as vasilhas plásticas que as continham, colocadas em banho-maria a $30 \pm 1^{\circ} \mathrm{C}$ dentro do laboratório. $\mathrm{O}$ experimento foi mantido com luz artificial em sua totalidade.

As plantas desenvolveram-se nessas condições por 48 horas. Após esse periodo, cada uma das seis telas de náilon contendo as vinte plântulas dos onze cultivares foi transferida para vasilha plástica, contendo, nas suas soluçōes tratamentos, respectivamente, $0,10,20,30,40$ e $50 \mathrm{mg} /$ litro de $\mathrm{Al}$ na forma de $\mathrm{Al}_{2}\left(\mathrm{SO}_{4}\right)_{3} \cdot 18 \mathrm{H}_{2} \mathrm{O}$.

A composição da solução tratamento foi basicamente um décimo da solução nutritiva completa, exceto que o fósforo foi omitidio e o ferro foi adicionado em quantidade equivalente como $\mathrm{FeCl}_{3}$ no lugar de $\mathrm{Fe}-\mathrm{CYDTA}$, como foi descrito por MOORE et alii (6). O fósforo foi omitido para evitar a possível precipitação do alumínio. Antes da transferência das telas para as soluções tratamentos, foram colocadas as necessárias quantidades de $\mathrm{Al}_{2}\left(\mathrm{SO}_{4}\right)_{3} \cdot 18 \mathrm{H}_{2} \mathrm{O}$ e o $\mathrm{pH}$ foi ajustado para 4,0 com solução $\mathrm{H}_{2} \mathrm{SO}_{4} 1 \mathrm{~N}$, evitando-se adicionar solução de $\mathrm{NaOH} 1 \mathrm{~N}$, que poderia causar a precipitação do alumínio pelo menos no local de queda da gota.

As plantas desenvolveram nas soluções tratamentos durante dez dias, sendo que o $\mathrm{pH}$ das soluções foi mantido o mais próximo possível de 4,0 , com ajustamentos diários.

Decorrido esse periodo, as plântulas foram retiradas das soluçōes tratamentos, determinando-se o crescimento da raiz primária de cada uma, medindo-se em milímetros seu comprimento. Após, foram separadas as raízes das partes aéreas das plântulas de cada culiivar submetido a crescimento em soluçōes contendo diferentes concentraçōes de alumínio. As raizes $e$ as folhas de cada tratamento foram colocadas para secar em estufa com temperatura de $45^{\circ} \mathrm{C}$ por cinco dias. No final desse período, foi determinado o peso seco das raízes e das folhas das vinte plântulas. As folhas secas foram analisadas quimicamente segundo o método de BATAGLIA et alii (2) visando à obtenção dos teores de $\mathrm{Ca}, \mathrm{Mg}, \mathrm{K}$ e $\mathrm{Al}$.

O delineamento estatístico empregado foi de parcelas subdivididas, com duas repetições, onde as parcelas foram compostas pelas seis dife- 
rentes concentrações de alumínio e as subparcelas, pelos cnze cultivares de arroz estudados.

Os dados de crescimento das raízes foram analisados estatisticamente, considerando-se a média das vinte plântulas de cada cultivar após a influência prejudicial do alumínio nas diferentes soluções. A comparação entre as médias de crescimento da raiz dos onze cultivares dentro de uma mesma concentração de aluminio e a comparação entre as médias de crescimento da raiz de um mesmo cultivar, em diferentes concentrações de alumínio, foram feitas pelo teste de Tukey (7).

\section{RESULTADOS E DISCUSSÃO}

O comprimento médio das raízes dos onze cultivares de arroz, após dez dias de crescimento em soluções nutritivas contendo seis diferentes níveis de $\mathrm{Al}^{3+}$ e mantendo-se a temperatura de $30 \pm 1^{\circ} \mathrm{C}$, encontra-se no quadro 1 e na figura 1 . Nas figuras 2 e 3 , acham-se ilustrados os crescimentos das raízes dos cultivares IAC-164 e IAC-899, respectivamente, cultivados em soluções nutritivas contendo 0,20 e $40 \mathrm{mg} / \mathrm{litro}$ de $\mathrm{Al}^{3+}$.

Os resultados da análise estatística deste experimento são apresentados no quadro 2. Verificaram-se, pelo teste F, efeitos ariamente significativos para concentrações de aluminio, cultivares e interação cultivares $\mathrm{x}$ concentrações de alumínio, quando foram estudades os dados de comprimento das raízes.

Comparando as médias dos diferentes cultivares estudados com Omg/litro de alumínio na solução tratamento, verificaram-se diferenças significativas no comprimento das raízes, sendo que os cultivares IAC-47, IAC-25, IAC-120, IAC-164, IAC-165, IAC-435, Pérola e Blue Bonnet, de porte alto, diferiram significativamente dos cultivares IAC-899, IR-8 e IR-841, de porte baixo, mostrando que os últimos, comparados com os demais, apresentam menor crescimento das raízes em soluçōes nutritivas, mesmo com ausência de $\mathrm{Al}^{3+}$, sendo, portanto, essa uma característica específica desses genótipos.

Quando foram utilizadas soluções tratamentos contendo $10 \mathrm{mg} /$ litro de $\mathrm{Al}^{3+}$, verificou-se que todos os cultivares apresentaram redução no comprimento médio das raízes. Nessas condiçōes, o 'IAC-120' apresentou maior crescimento das raízes, diferindo, pelo teste de Tukey ao nível de 5\%, dos cultivares Blue Bonnet, IR-8, IR-841, IAC-47 e IAC-899, não diferindo, porém, dos demais cultivares estudados. Os cultivares IR-8, IAC-899 e IR-841 não diferiram entre si e foram os que apresentaram maior sensibilidade à presença de $10 \mathrm{mg} /$ litro de $\mathrm{Al}^{3+}$ nas soluções, diferindo significativamente dos cultivares Pérola, Blue Bonnet, IAC-25, IAC-47, IAC-120, IAC-165, IAC-164 e IAC-435.

Nas soluções contendo 20 e $30 \mathrm{mg} /$ litro de $\mathrm{Al}^{3+}$, o cultivar IAC-25 foi o que apresentou maior crescimento das raízes, diferindo estatisticamente, porém, somente dos cultivares IR-8, IAC-899 e IR-841. 


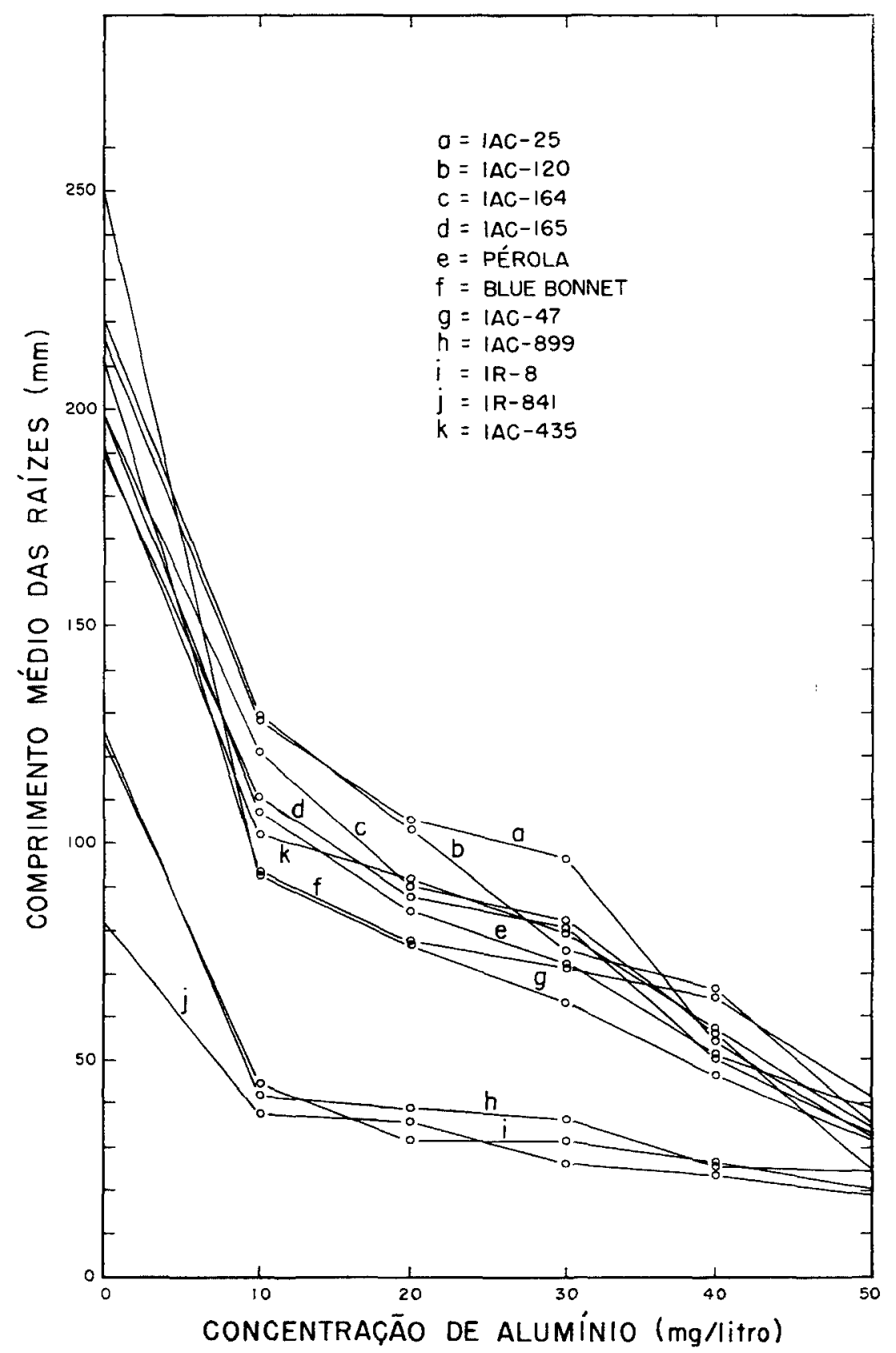

FIGURA 1 - Comprimento médio das raizes de onze cultivares de arroz medidos após dez dias de crescimento em soluçōes nutritivas contendo seis diferentes concentrações de alumínio, à temperatura de $30 \pm 1^{\circ} \mathrm{C}$. 


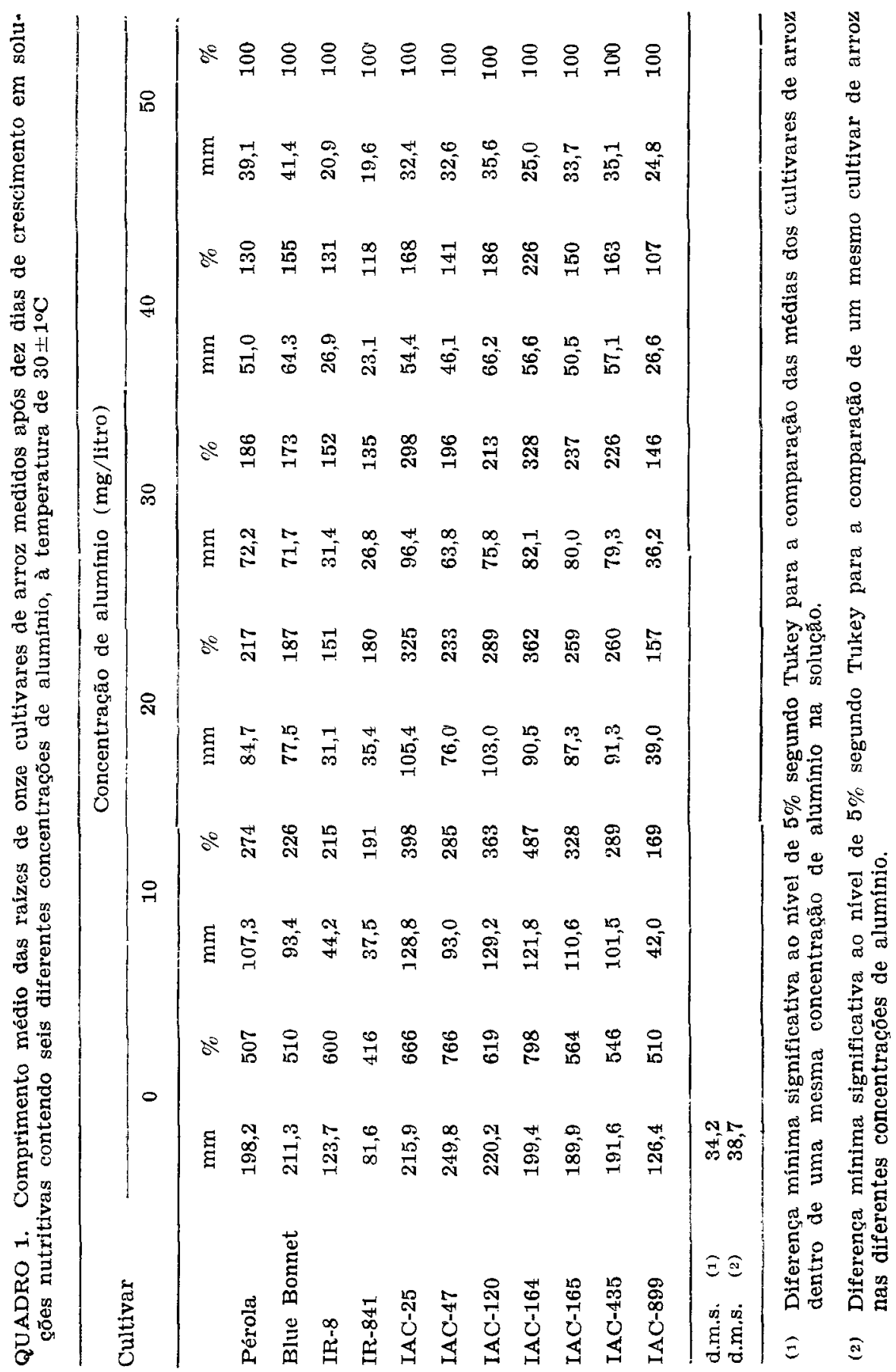




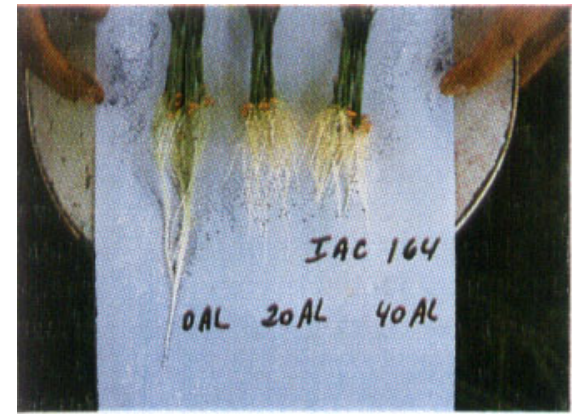

FICURA 2. Sistema radicular do culrivar IAC-164 após dez dias de crescimento em solucões nutritivas contendo 0,20 e $40 \mathrm{mg} /$ litro de alumínio, empregando-se a temperatura de $30 \pm 1^{\circ} \mathrm{C}$.

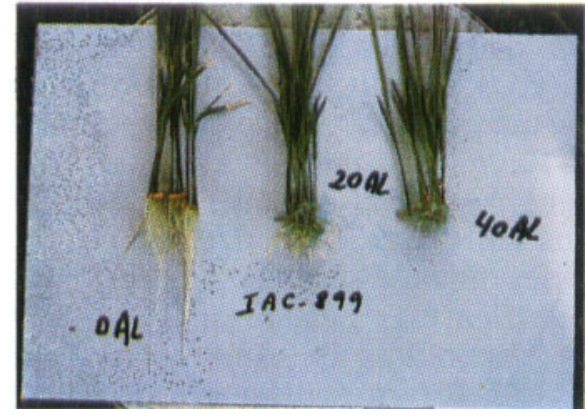

FIGURA 3. Sistema radicular do cultivar IAC-899 após dez dias de crescimento em soluçöes nutritivas contendo 0 , 20 e $4 \mathrm{cmg} /$ litro de aluminio, empregando-se a temperatura de $30 \pm 1^{\circ} \mathrm{C}$.

QUADRO 2. Análise da variância para crescimento da raiz de onze cultivares de arroz testados durante dez dias em soluções contendo seis diferentes concentrações de alumínio, empregando-se a temperatura de $30 \pm 1^{\circ} \mathrm{C}$

\begin{tabular}{lcc}
\hline Causas de variação & G.L. & Q.M. \\
\hline Repetições & 1 & 779,64 \\
Concentrações de Al3+ & 5 & $63088,15^{* *}$ \\
Erro I & 5 & 563,72 \\
Cultivares & 10 & $7435,34^{* *}$ \\
Cultivares x Concentrações de Al3* & 50 & $628,20^{* *}$ \\
Erro II & 60 & 104,74 \\
\hline
\end{tabular}

Total

131

** Efeitos significativos ao nivel de $1 \%$ pelo teste $\mathrm{F}$.

Os cultivares de arroz IAC-120 e Blue Bonnet apresentaram raízes mais compridas quando se adicionaram $40 \mathrm{mg} /$ litro de $\mathrm{Al}^{3 *}$ nas soluções tratamentos, diferindo pelo teste de Tukey ao nível de $5 \%$ dos cultivares IR-8, IAC-899 e IR-841, que, por sua vez, não diferiram dos cultivares IAC-25, IAC-47, IAC-165, IAC-164, IAC-435 e Pérola.

Considerando as soluçōes tratamentos com $50 \mathrm{mg} /$ litro de $\mathrm{Al}^{3+}$, verificou-se que não ocorreram diferenças significativas entre os cultivares estudados quanto ao comprimento das raízes. 
A diferença minima significativa para a comparação dos comprimentos das raízes de um mesmo cultivar submetido a crescimento em seis diferentes soluçōes tratamentos contendo $\mathrm{Al}^{3 \div}$ foi $38,7 \mathrm{~mm}$. Comparando os comprimentos das raizes dos cultivares estudados quando submetidos a $10 \mathrm{mg} /$ litro de $\mathrm{Al}^{3+}$ e a $50 \mathrm{mg} /$ litro de $\mathrm{Al}^{3+}$, verificou-se que todos tiveram reduzidos os seus comprimentos, porém o comprimento das raízes dos cultivares IR-8, IAC-899 e IR-841 a 10mg/litro não äiferiu daqueles observados a $50 \mathrm{mg} / \mathrm{litro}$, ao passo que foram encontradas diferenças significativas pela mesma comparação, para os outros cultivares. Logo, os resultados apresentados sugerem que os cultivares IR-8, IAC-899 ᄅ IR-841 foram sensíveis a $10 \mathrm{mg} /$ litro de $\mathrm{Al}^{3+}$ e que os cultivares Pérola, Blue Bonnet, IAC-25, IAC-47, IAC-120, IAC-164, IAC-165 e IAC-435 foram tolerantes, mesmo com teores de até $30 \mathrm{mg} /$ litro de $\mathrm{Al}^{3+}$ nas soluções. Esses resultados estão de acordo com os obtidos por CAMARGO et alii (3), MARTINEZ (5) e KONZAK et alii (4), e foram obtidos por um método mais simples onde somente uma medição de comprimento da raiz foi necessária.

Os pesos secos das raizes, das partes aéreas e totais de vinte plântulas de cada um dos cultivares estudados em soluçōes nutritivas contendo 0,10 e $50 \mathrm{mg} /$ litro de $\mathrm{Al}^{3-}$, encontram-se no quadro 3 . Verifica-se que o peso seco total e o das partes aéreas dos cultivares de arroz estudados tenderam a diminuir quando se adicionaram $50 \mathrm{mg} /$ litro de $\mathrm{Al}^{3+}$ quando comparados com 0mg/litro de $\mathrm{Al}^{3+}$, apesar de alguns cultivares mostrarem um peso maior quando se consideraram as soluções contendo $10 \mathrm{mg} / \mathrm{li}-$ tro de $\mathrm{Al}^{3+}$.

Considerando que o efeito primário do $\mathrm{Al}$ é a inibição do crescimento das raízes, que se tornam curtas e grossas, constatou-se que o peso seco das raízes dos cultivares Pérola, IAC-25, IAC-165 e IAC-435, mesmo apresentando raízes mais curtas em soluçóes com $50 \mathrm{mg} /$ litro de $\mathrm{Al}^{3+}$, mostraram um peso seco das raizes nessas condições maior do que quando comparados com o peso seco em soluções sem alumínio. Os cultivares sensiveis ao aluminio, tais como IR-8, IAC-899 e IR-841, apresentaram peso seco das raizes decrescendo à medida que foram aumentadas as concentrações de alumínio das soluçōes. O mesmo resultado fci obtido para os cultivares tolerantes Blue Bonnet, IAC-47, IAC-120 e IAC-164.

No quadro 4, encontram-se as concentracoes de $\mathrm{Ca}, \mathrm{Mg}$ e $\mathrm{K}(\%)$ determinadas nas folhas dos onze cultivares de arroz submetidos a crescimento durante dez dias em soluções nutritivas contendo 0,10 e $50 \mathrm{mg} / \mathrm{litro}$ de $\mathrm{Al}^{3+}$ e as concentrações de $\mathrm{Al}$ (ppm) dos mesmos cultivares estudados em soluções apresentando os teores de 10 e $50 \mathrm{mg} /$ litro de $\mathrm{Al}^{3+}$.

Os teores de aluminio aumentaram nas folhas em todos os cultivares à medida que foram aumentados os teores de $\mathrm{Al}^{3-}$ de 10 para $50 \mathrm{mg} / \mathrm{litro}$ nas soluçōes. 


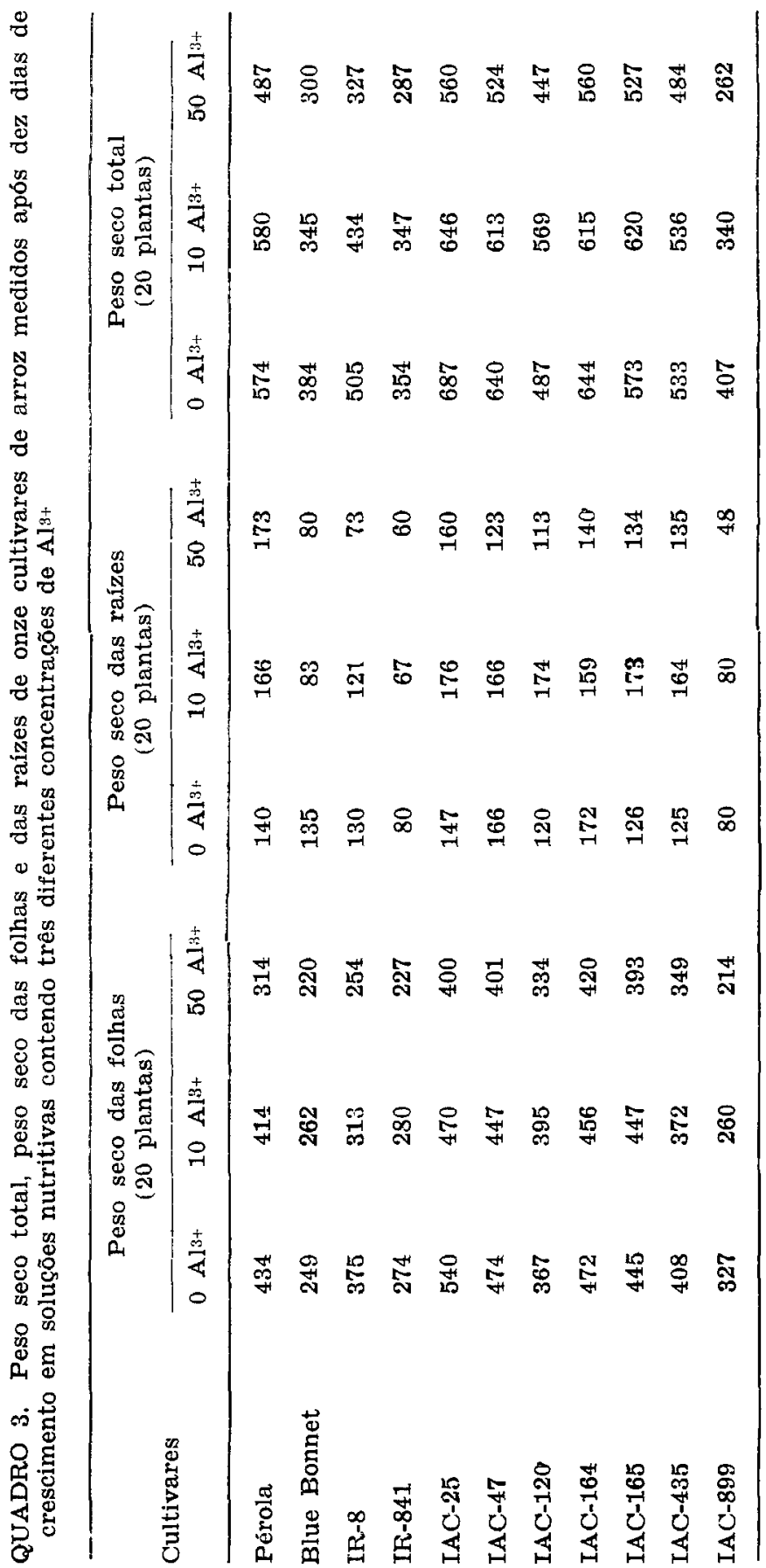




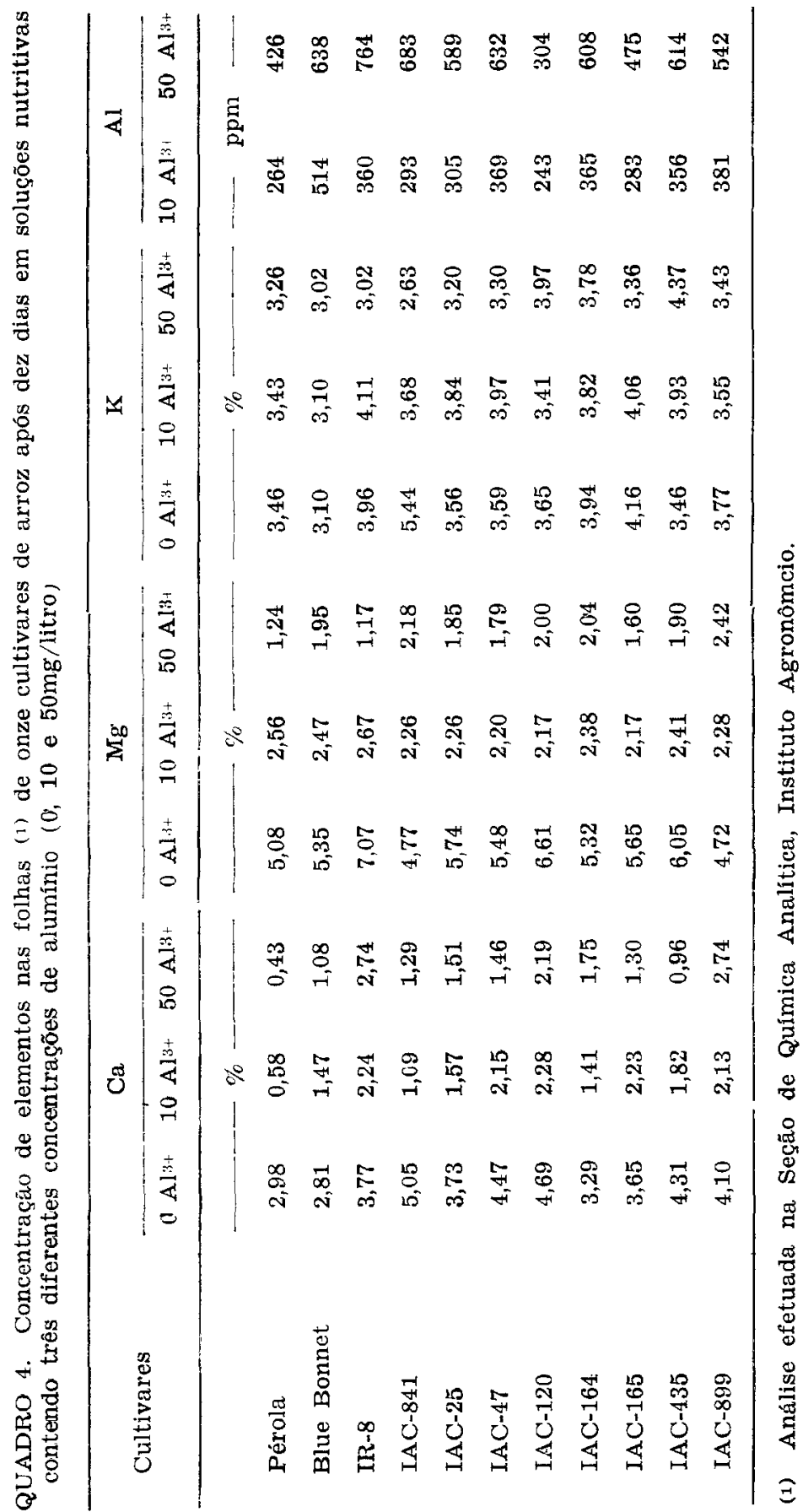


Foi observado que os teores de $\mathrm{Ca}, \mathrm{K}$ e $\mathrm{Mg}$ diminuíram nas partes aéreas em todos os cultivares estudados à medida que foram aumentados os teores de $\mathrm{Al}^{3+}$ de 0 a $50 \mathrm{mg} /$ litro nas soluções.

\title{
4. CONCLUSÕES
}

a) A técnica empregada para o estudo de cultivares de arroz a crescentes concentraçōes de aluminio em soluções rutritivas foi eficiente, possibilitando a separação de cultivares tolerantes e sensiveis, em dez dias, através de uma única medida do comprimento das raizes das plântulas estudadas.

b) Os cultivares IR-8, IAC-899 e IR-841 foram sensiveis quando se empregaram $10 \mathrm{mg} /$ litro de $\mathrm{Al}^{3+}$ nas soluções, ao passo que os cultivares IAC-435, IAC-120, IAC-164, IAC-165, IAC-25, IAC-47, Pérola e Blue Bonnet mostraram tolerância a essa concentração, mantendo-se tolerantes mesmo quando se empregaram $20 \mathrm{mg} /$ litro de $\mathrm{Al}^{3+}$. Todos os cultivares foram sensiveis quando foi aplicada a quantidade de alumínio na solução equivalente a uma concentração de $50 \mathrm{mg} /$ litro.

c) Os teores de $\mathrm{Al}$ aumentaram e os de $\mathrm{Ca}, \mathrm{Mg}$ e $\mathrm{K}$ diminuíram na matéria seca da parte aérea de todos os cultivares, à medida que se aumentaram as concentrações de Al nas soluçōes nutritivas.

\section{SUMMARY}

\section{EFFECT OF DIFFERENT ALUMINUM CONCENTRATIONS IN NUTRIENT SOLUTION ON THE TOLERANCE OF RICE CULTIVARS}

\begin{abstract}
Eleven rice cultivars were studied in relation to aluminum toxicity using six different levels of this element $(0,10,20,30,40$ and $50 \mathrm{mg} / 1)$ in nutrient solution under constant temperature $\left(30 \pm 1^{\circ} \mathrm{C}\right)$ and $\mathrm{pH}=4.0$. Plant tolerance was measured taking into account the central primary root length and the tota? leaf and root dry weight. The presence of aluminum in the solution produced harmfull effects on all rice cultivars studied. The rice cultivars IR-8, IR-841 and IAC-899 were sensitive when it was added $10 \mathrm{mg} / 1$ of $\mathrm{Al} 3+$ into the solution and the cultivars IAC-435, IAC-120, Pérola, Blue Bonnet, IAC-164, IAC-25, IAC-165 and IAC-47 showed tolerance to this $\mathrm{Al}$ concentration. The last cultivars presented tolerance even with $20 \mathrm{mg} / 1$ of $\mathrm{Al}^{3+}$ in the solution. All cultivars were sensitive with $50 \mathrm{mg} / \mathrm{I}$ of $\mathrm{Al}$ in the solution. The aluminum concentration increased and the $\mathrm{Ca}, \mathrm{Mg}$ and $\mathrm{X}$ concentrations decreased in the leaf dry matter, for all cultivars under study, as aluminum concentration in nutrient solutions increased from 0 to $50 \mathrm{mg} / \mathrm{l}$.
\end{abstract}

\section{REFERENCLAS BIBLIOGRAFICAS}

1. ALUMINUM toxicity in upland soils. In: ANNUAL REPOR'T FOR 1973. LOs Baños-Philippines, The International Rice Research Institute, 1974. p.103.

2. BATAGLIA, O.C.; TEIXEIRA, J.P.F.; FURLANI, P.R.; FURLANI, A.M.O.; GALLO, J.R. Métodos de análise quimica de plantas. Campinas, Instituto Agronômico, 1978. 31p. (Circular 87) 
3. CAMARgO, C.E.O.; CAMARgo, O.B.A.; SOUZA, D.M. Tolerancia de cultivares de arroz a diferentes níveis de alumínio em solução nutritiva. Bragantia, Campinas, $42: 191-201,1983$.

4. KONZAK, C.F.; POLLE, E.; KITTRICK, J.A. Screening several crops for aluminum tolerance. In: WRIGHT, Madison J., ed. Workshop on Plant Adaptation to Mineral Stress in Problem Soils, Beltsville, Maryland, 1976. Proceedings. Ithaca, Cornell University, 1976. p.311-327.

5. MARTINEZ, C. Aluminum toxicity studies in rice (Oryza sativa L.). Corvallis, Universidade Estadual de Oregon, 1977. 113p. Tese de Doutoramento.

6. MOORE, D.P.; KRONSTAD, W.E.; METZGER, R. Screening wheat for aluminum tolerance. In: WRIGHT, Madison J., ed. Workshop on Plant Adaptation to Mineral Stress in Problem Soils, Beltsville, Maryland, 1976. Procedings. Ithaca, Cornell University, 1976. p.287-295.

7. STEEL, R.G.D. \& TORRIE, J.H. Principles and procedures of statistics. New York, Mc Graw-Hill, 1960. 481p. 